\title{
Survival time of juvenile pen shell Atrina pectinata (Bivalvia: Pinnidae) in hyposaline water
}

\author{
Takeo Kurihara $\cdot$ Shoji Nakano $\cdot$ Yukihiko Matsuyama $\cdot$ Kazumasa Hashimoto $\cdot$ \\ Katsumasa Yamada $\cdot$ Atsushi Ito $\cdot$ Masaei Kanematsu
}

Received: 24 June 2017/ Accepted: 18 November 2017/Published online: 5 December 2017

(C) The Author(s) 2017. This article is an open access publication

\begin{abstract}
Survival time of juvenile pen shell Atrina pectinata (shell length $\approx 34 \mathrm{~mm}$ ) exposed to hyposaline water without sediments was investigated in laboratory experiments. The bivalves were individually maintained in rearing cups in which salinity was decreased either gradually (over 1-11 h to 12 salinities ranging from 0 to ca. $34 \mathrm{ppt}$ ) or rapidly (directly to 21 salinities) at 12 and $24{ }^{\circ} \mathrm{C}$. When the environmental salinity was gradually decreased, survival time differed markedly between the bivalves exposed to: salinities $\leq 18.6 \mathrm{ppt}$ (survival time $<20 \mathrm{~h}$ in general) vs. $\geq 21.1 \mathrm{ppt}\left(>83 \mathrm{~h}\right.$ ) at $24{ }^{\circ} \mathrm{C}$; and between salinities $\leq 15.1 \mathrm{ppt}(<34 \mathrm{~h})$ vs. $\geq 17.2 \mathrm{ppt}(>83 \mathrm{~h})$ at $12{ }^{\circ} \mathrm{C}$. When the environmental salinity was rapidly decreased, survival time, again, differed markedly between the bivalves exposed to: salinities $\leq 15.9 \mathrm{ppt}(<20 \mathrm{~h}$ in general) vs. $\geq 17.7 \mathrm{ppt}$ $(>140 \mathrm{~h})$ at $24{ }^{\circ} \mathrm{C}$; and salinities $\leq 21.3 \mathrm{ppt}\left(<38 \mathrm{~h}\right.$ in general) vs. $\geq 22.3 \mathrm{ppt}(>140 \mathrm{~h})$ at $12{ }^{\circ} \mathrm{C}$. Such sharp decreases in survival time due to reduced salinity led to the selected, statistical models that assume either a sharp exponential increase or stepwise hike in hazard (instantaneous mortality rate) according to salinity reduction. These data and models indicate that juvenile A. pectinata should not be kept at salinities $<21 \mathrm{ppt}$ for periods $>1$ day in environments without sediments.
\end{abstract}

Keywords Pen shell · Atrina pectinata Lineage 2 - Survival analysis · Low salinity · Gradual and rapid decreases $\cdot$ Temperature

\section{Introduction}

Salinity is one of major environmental factors determining the physiology and behavior of marine animals (Kinne 1966). A change in environmental salinity leads to a difference in osmotic pressure between the environment and tissue cells, which is stressful for marine animals. In shallow seas salinity changes owing to various factors (e.g. tidal currents, terrestrial runoff, rain). Such changes often lead to the mortality of various

T. Kurihara $(\bowtie) \cdot$ S. Nakano · Y. Matsuyama $\cdot$ K. Hashimoto $\cdot$ K. Yamada

Seikai National Fisheries Research Institute, Japan Fisheries Research and Education Agency, 1551-8 Taira-machi,

Nagasaki 851-2213, Japan

e-mail: takeo@affrc.go.jp

A. Ito $\cdot$ M. Kanematsu

National Research Institute of Fisheries and Environment of Inland Sea, Japan Fisheries Research and Education Agency, 2-

17-5 Maruishi, Hatsukaichi, Hiroshima 739-0452, Japan 
animals within such areas (e.g. Kinne 1966; Gillanders and Kingsford 2002). The influence of salinity changes on survival has been studied for a diverse range of animals (Newell 1976).

These studies include hyposaline endurance of marine bivalves (e.g. Leyva-Valencia et al. 2001; Marsden 2004; Rupp and Parsons 2004; Holmes and Miller 2006; Matsuda et al. 2008; McLeod and Wing 2008; Jansen et al. 2009; Yuan et al. 2010; Yamamoto and Handa 2011). The studies on bivalves revealed that their endurance of hyposaline conditions depends on various factors including species specificity, life stage, temperature, and the rate of salinity change. That is, some species tolerate extremely low salinities such as freshwater (e.g., Corbula gibba, Austrovenus stutchburyi, Phragmites australis, Mytella charruana; Holmes and Miller 2006; McLeod and Wing 2008; Yuan et al. 2010), whereas some species cannot tolerate even 75\% seawater (e.g., Patinopecten yessoensis, Pecten albicans; Funakoshi et al. 1985). Juveniles and adults often show different hyposaline endurance (e.g., Chlamys opercularis, Mytella charruana, Perna viridis; Paul 1980; Yuan et al. 2016). Extremely high or low water temperature leads to lowered hyposaline endurance in some species (Chlamys opercularis, Mytella charruana, Perna viridis; Paul 1980; Yuan et al. 2016). More rapid decreases in salinity possibly lead to lower hyposaline endurance, since some bivalves cannot change the densities of osmolites in their cells quickly enough (Shumway et al. 1977).

The pen shell Atrina pectinata (called "tairagi" in Japanese; see "Materials" for its taxonomic problems) is an important fishery resource in Japan. For example, its catch exceeded a value of 1 billion yen (about 9 million US dollars) for the Ariake Sea in Saga Prefecture in 1990 (Koga and Aramaki 2013). The resource has greatly decreased in recent years especially in the Ariake Sea (Koga and Aramaki 2013). For example, the catch (wet weight of soft tissue and shells) decreased from $>10,000$ metric tons in the 1960s to $<10$ metric tons in the 2010s in Saga Prefecture. To regain the stock level in Japan, artificial hatchery-rearing techniques have been recently developed (Fisheries Research Agency et al. 2017). In addition, the transplantation of juveniles has been examined on tidal muddy flats (Aramaki and Tsukuda 2014; Fisheries Research Agency et al. 2017), which are promising transplantation sites because transplanted wild pen shells have often survived better on tidal flats than in subtidal areas in the Ariake Sea (Yoshida et al. 2007).

Occasionally in rearing systems and frequently on tidal flats A. pectinata juveniles will be exposed to low salinities $<20$ ppt owing to rain and terrestrial runoff (Kurihara 2017; Kurihara personal data). A. pectinata juveniles are sometimes reared in hatcheries without sediments (Fisheries Research Agency et al. 2017) and are often transplanted onto tidal flats without being embedded into the sediments (Aramaki and Tsukuda 2014), because such treatment using sediments is labor intensive. Therefore, A. pectinata juveniles can be exposed to low-salinity water without being covered by sediments, and thus its endurance against low salinity without sediments needs to be tested. In addition, as with foregoing other species (Chlamys opercularis, Mytella charruana, Perna viridis), A. pectinata juveniles may also change their hyposaline endurance in response to water temperature and rapidness of salinity decrease, and thus such potential interactions also needs to be studied. At present, information on hyposaline endurances of A. pectinata is only available for the adult specimens in an experiment without sediments by Yamamoto and Handa (2011) in which the hyposaline endurance was tested at one level of water temperature $\left(28{ }^{\circ} \mathrm{C}\right)$ with salinity decreased rapidly.

We conducted laboratory experiments with environmental salinity being decreased either gradually or rapidly in either warm or cold water to examine how hyposaline water in these condition affects the survival time of juvenile A. pectinata with no sediments. In addition, the present study examined a new statistical model that assumes a stepwise sharp increase of hazard (i.e., instantaneous mortality rate), not a classical exponential increase of hazard (Kleinbaum and Klein 2012), according to the decrease of salinity. This is because the survival time of some bivalves sharply changes according to a small change of salinity (Leyva-Valencia el al. 2001; Yamamoto and Handa 2011) and thus the stepwise increase of hazard appears to better fit such data.

\section{Materials}

Experimental specimens were artificially hatched in July 2014 at the Seikai National Fisheries Research Institute from the eggs of adult pen shells collected in the Ariake Sea, Japan. The orthodox species name at present for these pen shells is unclear owing to the taxonomic confusion of Atrina (Lemer et al. 2014). Yet, these pen shells all have been confirmed to be identical to "Atrina pectinata Lineage 2" (sensu Liu et al. 2011) 
by the analyses of the mtDNA COI region (Hashimoto, personal data). Therefore, we provisionally call our material "Atrina pectinata Lineage 2" or "Atrina pectinata".

In recent years pen shells in the Ariake Sea mainly consist of A. pectinata Lineage 2 (>90\% of specimens; Aramaki 2013; Hashimoto, personal data). Considering this, we judge that most pen shells collected from the Ariake Sea in recent studies (e.g., Yamamoto and Handa 2011; Koga and Aramaki 2013) consist of A. pectinata Lineage 2. Note that these pen shells were called "Atrina lischkeana" in some of recent studies (e.g., Yamamoto and Handa 2011).

Juvenile A. pectinata had been reared since its production in the laboratory of Seikai National Fisheries Research Institute. The specimens were kept in running seawater that had been sand-filtered. During the present study, the temperature ranged from $13.3{ }^{\circ} \mathrm{C}$ (February) to $18.6{ }^{\circ} \mathrm{C}$ (April), and the salinity from 33 and 34 ppt. The specimens were acclimated to the experimental water temperatures (either 12 or $24{ }^{\circ} \mathrm{C}$ ) for $>10$ days before the start of the experiment. The specimens were fed with Isochrysis sp., Pavlova sp. and Chaetoceros gracilis F. Schütt, 1895 before the start of the experiment but not during the experiment (120-140 h). The stopping of feeding during the experiment was necessary to keep the salinity of water as a predetermined level, because feeding the juveniles involves addition of phytoplankton culture medium to the water. Since juvenile A. pectinata survives experiments lasting for $>300 \mathrm{~h}$ without food (Nagasoe, personal communication), the stopping of feeding during our experiment $\leq 140 \mathrm{~h}$ is unlikely to significantly affect the survival time of the juvenile.

The hyposaline water to which experimental specimens were to be exposed was prepared by mixing distilled water at a predetermined dilution rate with the $100 \%$ seawater. The $100 \%$ seawater was what the specimens in the laboratory were being acclimated to. The salinity (ppt) of the $100 \%$ seawater varied between experimental days owing to the condition of the sea near the water intake. As a result, the salinity (ppt) somewhat varied among the replications of the same dilution rate. Considering the irregular variations of salinity, the salinity (ppt) attained for each replication was measured during the experiments with a salinometer EC300 (YSI Co.). The measurements for every experiment were regarded as an explanatory variable of the ratio scale (Upton and Cook 2005).

\section{Experimental methods}

Juvenile A. pectinata were exposed to various levels of low salinity at 12 and $24{ }^{\circ} \mathrm{C}$. Salinity was either gradually or rapidly decreased (hereafter called "gradual-salinity-decrease experiment" and "rapid-salinitydecrease experiment", respectively). To prevent the influences of other specimens, each specimen was individually put into a cup with a different combination of salinity and temperature. The mean \pm SD shell length (no. of individuals) of A. pectinata was $31.7 \pm 2.8 \mathrm{~mm}$ (24) for the gradual-salinity-decrease experiment and $36.1 \pm 3.5 \mathrm{~mm}$ (42) for the rapid-salinity-decrease experiment.

The gradual-salinity-decrease experiment was conducted in February 2015. The twenty-four specimens were allocated to the combinations of 12 dilutions $\times 2$ temperatures. The dilutions were of 12 levels: 100,80 , $60,55,50,45,40,35,30,20,10$, and $0 \%$ of the initial salinity that the specimens had been acclimated to. The salinities realized (ppt) were measured and analyzed as an explanatory variable in the present study.

Before the start of the gradual-salinity-decrease experiment, 24 experimental cups (radius $60 \mathrm{~mm}$, height $147 \mathrm{~mm}$ ) were prepared, which contained $800 \mathrm{~mL}$ of non-diluted, $0.2-\mu \mathrm{m}$ filtered seawater. Half the cups were put in a water bath of $12{ }^{\circ} \mathrm{C}$ and the other half in another bath of $24{ }^{\circ} \mathrm{C}$. One experimental specimen was put into each cup at the start of this experiment. Subsequently, the water in each cup (except for the two cups predetermined to contain $100 \%$ seawater) was in part exchanged with distilled water of the same temperature to dilute the salinity in a stepwise way: first, from $100 \%$ seawater to $80 \%$ seawater; second, from 80 to $60 \%$; third, from 60 to $55 \%$; fourth, from 55 to $50 \%$; etc. The dilution in a cup was stopped when the salinity in the cup attained the predetermined level. One hour was consumed from a dilution to the next dilution. Therefore, cups predetermined for lower salinities needed a longer time before reaching its determined level. The gradual-salinity-decrease experiment lasted for $120 \mathrm{~h}$, and the water in each cup was changed with new water of the same temperature and salinity every day.

During the gradual-salinity-decrease experiment each specimen was checked for survival intermittently 19 times in total. Specimens were regarded as dead that had opened valves and, when stimulated with a glass rod, did not move the valves or soft tissue. The remaining specimens, which had not been regarded as dead 
throughout the experiment, were confirmed to be alive in a post-experimental check in which these specimens were found to excrete and/or move the valves in $100 \%$ seawater containing the phytoplankton Isochrysis sp.

The rapid-salinity-decrease experiment was conducted in April 2015 in a similar manner to the gradualsalinity-decrease experiment, but all specimens were exposed to rapid, sharp decreases of salinity from $100 \%$ seawater to $\leq 100 \%$ seawater. In the rapid-salinity-decrease experiment, 42 specimens were allocated to the combinations of 21 dilutions $(100,95,90, \ldots, 5$, and $0 \%$ seawater $) \times$ two temperatures $\left(12\right.$ and $\left.24{ }^{\circ} \mathrm{C}\right)$. These specimens were transferred to the water of these conditions directly from tanks containing $100 \%$ seawater of the same temperatures. The rapid-salinity-decrease experiment lasted for $140 \mathrm{~h}$, and the survival of specimens was checked 28 times in total in a similar manner to the gradual-salinity-decrease experiment.

\section{Statistical modelling}

The survival time of juvenile A. pectinata was recorded as not a time point but a time range ("intervalcensored data" sensu Kleinbaum and Klein 2012). That is, if a specimen was found to be alive at the $i$ th observation and to be dead at the $(i+1)$ th observation, the survival time was recorded as the time range covering the two observations. In the case that the $i$ th observation was the last observation of the experiment, the survival time was recorded as the time range later than the last observation. The minimum and maximum values in the range of a survival time are hereafter called the "min. survival time" and "max. survival time".

The effect of low salinity on the survival time of juvenile A. pectinata was analyzed with specific statistical models for each experiment and temperature. The models were modified from the parametric survival analysis (Dobson and Barnett 2008; Kleinbaum and Klein 2012). The models assume that a specimen exposed to a low salinity would follow one of the six patterns (Fig. 1) of the relationship between low salinity and instantaneous mortality rate (namely, hazard; " $h$ " hereafter).

i. Null-constant model. The equation is:

$$
h=c
$$

where $c$ denotes a constant $>0$. The survival time under this model follows an exponential distribution (Upton and Cook 2005), the rate parameter of which is a constant. The biological meaning of this model is that there is neither hyposaline stress nor temporally increasing stress.

ii. Null-accumulation model. The equation is:

$$
h=c \cdot t
$$

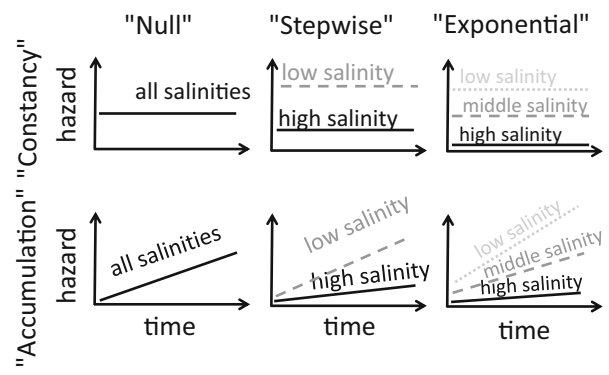

Fig. 1 Six statistical models for possible relationships of hazard (i.e., instantaneous mortality rate) against time at different salinities. Hazard is assumed to be: independent of salinity (the null models); dependent on whether or not salinity exceeds a threshold (the stepwise models); or exponentially variable according to salinity (the exponential models). Hazard is assumed to be either independent of time (the constancy models) or dependent (the accumulation models) 
where $c$ denotes a constant $(>0)$ and $t$ the exposure time. The survival time under this model follows a Rayleigh distribution (Upton and Cook 2005), the scale parameter of which is a constant. The biological meaning of this model is that there is no hyposaline stress and some other stresses increase over time.

iii. Exponential-constant model. The equation is:

$$
h=c \cdot \exp (-k \cdot s)
$$

where $c$ denotes a constant $(>0), k$ the slope $(>0)$, and $s$ the salinity. The survival time under this model follows an exponential distribution, the rate parameter of which is a function of salinity. The biological meaning of this model is that stress exponentially increases with decreased salinity and is temporally constant.

iv. Exponential-accumulation model. The equation is:

$$
h=c \cdot \exp (-k \cdot s) \cdot t
$$

where $c$ denotes a constant $(>0), k$ the slope $(>0), s$ the salinity, and $t$ the exposure time. The survival time under this model follows a Rayleigh distribution, the scale parameter of which is a function of salinity. The biological meaning of this model is that stress exponentially increases with decreased salinity and increases over time.

v. Stepwise-constant model. The equation is:

$$
h=c_{1}+c_{2} \cdot f(s, \tau)
$$

where $c_{1}$ and $c_{2}$ denote a constant $(>0), s$ salinity, $\tau$ threshold, and $f$ a step function ( 1 when $s<\tau$, and 0 when $s \geq \tau$ ). The biological meaning of this model is that stress increases in a stepwise manner when salinity was decreased below a threshold and is temporally constant.

vi. Stepwise-accumulation model. The equation is:

$$
h=\left\{c_{1}+c_{2} \cdot f(s, \tau)\right\} \cdot t
$$

where $c_{1}$ and $c_{2}$ denote a constant $(>0), s$ salinity, $\tau$ threshold, $f$ the foregoing step function, and $t$ the exposure time. The biological meaning of this model is that stress increases in a stepwise manner when salinity was decreased below a threshold and increases over time.

For each experiment and temperature, the parameters of the above six models were determined by the maximum likelihood estimation (Dobson and Barnett 2008) as follows. (1) The initial values of parameters were arbitrarily chosen. (2) From the parameters, the hazard for each specimen was calculated and the specimen's survival curve was determined. (3) From the survival curve, the likelihood of the specimen dying between the min. and max. survival time recorded was calculated. (4) The logarithm of the likelihood was summed across all the specimens. (5) The procedures 2-4 were repeated with the values of parameters changed by the Nelder-Mead simplex method (Upton and Cook 2005) to maximize the sum of the logarithm of the likelihood. This maximization algorithm was performed with the function "optim" in R (R Core Team 2015).

From the maximized sum of the logarithm of the likelihood and the number of parameters, the Bayesian information criterion (BIC) was calculated for each model (Upton and Cook 2005). The model with the lowest BIC was regarded as the best model. 


\section{Results}

Gradual-salinity-decrease experiment

At both temperatures the survival time and expected LT50 (median lifetime) of juvenile A. pectinata sharply decreased owing to a small decrease $(<5 \mathrm{ppt})$ in salinity, as follows.

For the high temperature $\left(24^{\circ} \mathrm{C}\right)$ all juveniles survived the 83 -h observation at salinities $\geq 21.1 \mathrm{ppt}$, whereas all juveniles died at salinities $\leq 18.6 \mathrm{ppt}$ (Fig. 2) with the max. survival time $<20 \mathrm{~h}$ except for one specimen. In a sense, such a sharp difference in the max. survival time between high and low salinities did not correspond with the result of model selection (Table 1): the exponential-constant model showed a better, i.e. lower, BIC (60.2) than the stepwise models (64.7 and 73.7). The sharp difference, however, corresponded with the expected LT50 of the selected, exponential-constant model, which sharply decreased with the decrease of salinity from 20 to 15 ppt (Fig. 3).

For the low temperature $\left(12^{\circ} \mathrm{C}\right)$ all specimens survived the 83 -h observation at salinities $\geq 17.2 \mathrm{ppt}$, whereas all specimens died at salinities $\leq 15.1 \mathrm{ppt}$ (Fig. 2) with the max. survival time $<33.6 \mathrm{~h}$. Such a sharp difference in the max. survival time between salinities corresponded with a result that the stepwise-accumulation model showed the best BIC, 26.3, among the six models (Table 1). This selected model estimated the lethal salinity threshold to be 15.1-17.1 ppt. At salinities $<15 \mathrm{ppt}$, the max. survival time and expected LT50 (18.3 h) were longer for lower temperature (Fig. 3).

Rapid-salinity-decrease experiment

At both temperatures, again, the survival time and expected LT50 sharply decreased owing to a small decrease in salinity $<5 \mathrm{ppt}$.

For the high temperature, all specimens except one survived the 140 -h observation at salinities $\geq 17.7 \mathrm{ppt}$, whereas all specimens died at salinities $\leq 15.9 \mathrm{ppt}$ (Fig. 4). At salinities $\leq 15.9 \mathrm{ppt}$ the max. survival time varied among specimens from 13 to $20 \mathrm{~h}$, neither increasing nor decreasing according to salinity. Such a sharp difference in the max. survival time between high and low salinities corresponded with a result that the stepwise-accumulation model showed the best BIC, 61.4 (Table 2). This model estimated the lethal salinity threshold to be 15.9-17.7 ppt and the LT50 below the threshold to be $12.4 \mathrm{~h}$.

At the low temperature all specimens survived the $140-\mathrm{h}$ observation at salinities $\geq 22.3 \mathrm{ppt}$, whereas all specimens died at salinities $\leq 21.3 \mathrm{ppt}$ (Fig. 4). Such a difference in survival time corresponded with a result that the stepwise-accumulation model showed the best BIC, 90.7 (Table 2). This model estimated the lethal salinity threshold to be 18.6-21.3 ppt and the LT50 below the threshold to be $18.0 \mathrm{~h}$. At salinities $<15.0 \mathrm{ppt}$ the max. survival time (Fig. 4) and expected LT50 (Fig. 3) were somewhat longer for lower temperatures, as found in the gradual-salinity-decrease experiment. Expected LT50 for the rapid-salinity-decrease experiment

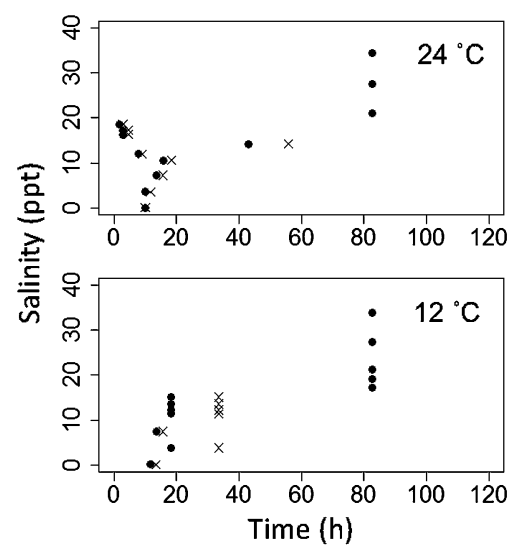

Fig. 2 Results of the gradual-salinity-decrease experiment at 24 and $12{ }^{\circ} \mathrm{C}$. Filled circles: the last time a specimen was found to be alive. Crosses: the first time a specimen was found to be dead 
Table 1 Results of statistical model selection for the gradual-salinity-decrease experiment

\begin{tabular}{|c|c|c|c|}
\hline Model & Aspect & $24^{\circ} \mathrm{C}$ & $12{ }^{\circ} \mathrm{C}$ \\
\hline Null-Constant & No. of parameters & 1 & 1 \\
\hline \multirow[t]{3}{*}{$h=c$} & Data size & 12 & 12 \\
\hline & $\mathrm{BIC}$ & 81.2 & 48.0 \\
\hline & Parameter $c$ & 0.0244 & 0.0122 \\
\hline Null-Accumulation & No. of parameters & 1 & 1 \\
\hline \multirow[t]{3}{*}{$h=c \cdot t$} & Data size & 12 & 12 \\
\hline & $\mathrm{BIC}$ & 103.5 & 54.2 \\
\hline & Parameter $c$ & 0.0008 & 0.0004 \\
\hline Exponential-Constant & No. of parameters & 2 & 2 \\
\hline \multirow[t]{4}{*}{$h=c_{1} \cdot \exp \left(-c_{2} \cdot \mathrm{s}\right)$} & Data size & 12 & 12 \\
\hline & $\mathrm{BIC}$ & 60.2 & 31.7 \\
\hline & Parameter $c_{1}$ & $1.578 \mathrm{E}+00$ & $4.091 \mathrm{E}-01$ \\
\hline & Parameter $c_{2}$ & $2.463 \mathrm{E}-01$ & $2.349 \mathrm{E}-01$ \\
\hline Exponential-Accumulation & No. of parameters & 2 & 2 \\
\hline \multirow[t]{4}{*}{$h=c_{1} \cdot \exp \left(-c_{2} \cdot s\right) \cdot t$} & Data size & 12 & 12 \\
\hline & BIC & 76.3 & 27.2 \\
\hline & Parameter $c_{1}$ & $1.726 \mathrm{E}+00$ & $2.020 \mathrm{E}-01$ \\
\hline & Parameter $c_{2}$ & $4.177 \mathrm{E}-01$ & $3.802 \mathrm{E}-01$ \\
\hline Stepwise-Constant & No. of parameters & 3 & 3 \\
\hline \multirow[t]{5}{*}{$h=c_{1}+c_{2} \cdot f(s, \tau)$} & Data size & 12 & 12 \\
\hline & BIC & 64.7 & 31.4 \\
\hline & Parameter $c_{1}$ & $4.830 \mathrm{E}-10$ & $1.567 \mathrm{E}-09$ \\
\hline & Parameter $c_{2}$ & $9.123 \mathrm{E}-02$ & $5.871 \mathrm{E}-02$ \\
\hline & Parameter $\tau$ & $18.6-21.1$ & $15.0-17.1$ \\
\hline Stepwise-Accumulation & No. of parameters & 3 & 3 \\
\hline \multirow[t]{5}{*}{$h=\left\{c_{1}+c_{2} \cdot f(s, \tau)\right\} \cdot t$} & Data size & 12 & 12 \\
\hline & $\mathrm{BIC}$ & 73.7 & 26.3 \\
\hline & Parameter $c_{1}$ & $7.554 \mathrm{E}-11$ & $0.000 \mathrm{E}+00$ \\
\hline & Parameter $c_{2}$ & $6.100 \mathrm{E}-03$ & $4.160 \mathrm{E}-03$ \\
\hline & Parameter $\tau$ & $18.6-21.1$ & $15.0-17.1$ \\
\hline
\end{tabular}

$h$ hazard or instantaneous mortality rate, $c, c_{1}, c_{2}$ parameters for the effect of salinity, $\tau$ threshold of salinity (determined as a range), $s$ salinity, $f(s, \tau)$ step function ( 1 when $s<\tau$, and 0 when $s \geq \tau)$. The lowest BIC for each temperature is shown in bold numericals

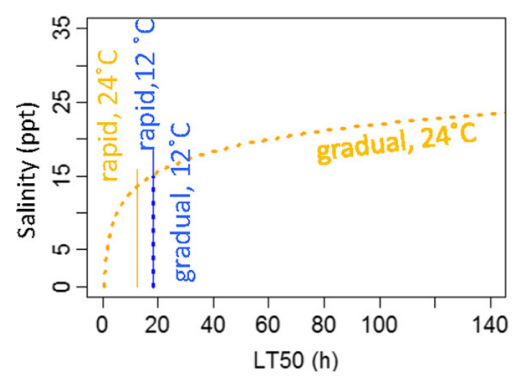

Fig. 3 Estimates of LT50 (median life time) for each experiment (gradual-salinity-decrease experiment: dotted lines, rapidsalinity-decrease experiment: continuous lines) at each temperature $\left(24{ }^{\circ} \mathrm{C}\right.$ : orange lines, $12{ }^{\circ} \mathrm{C}$ : blue lines). Except for the gradual-salinity-decrease experiment at $24{ }^{\circ} \mathrm{C}$, only the LT50 at salinities below a threshold is presented because the LT50 at salinities exceeding a threshold was longer than the experimental durations 


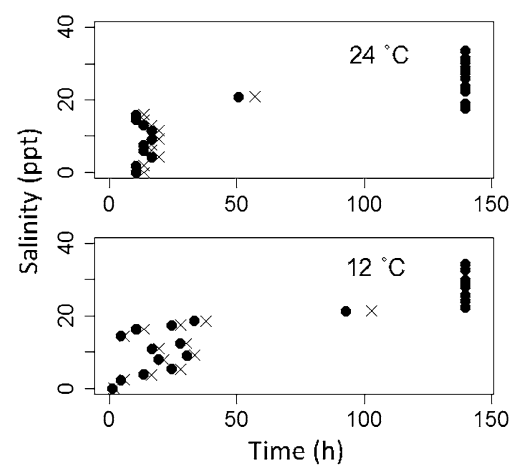

Fig. 4 Results of the rapid-salinity-decrease experiment at 24 and $12{ }^{\circ} \mathrm{C}$. Filled circles: the last time a specimen was found to be alive. Crosses: the first time the specimen was found to be dead

Table 2 Results of statistical model selection for the rapid-salinity-decrease experiment

\begin{tabular}{|c|c|c|c|}
\hline Model & Aspect & $24^{\circ} \mathrm{C}$ & $12^{\circ} \mathrm{C}$ \\
\hline Null-Constant & No. of parameters & 1 & 1 \\
\hline \multirow[t]{3}{*}{$h=c$} & Data size & 21 & 21 \\
\hline & $\mathrm{BIC}$ & 109.0 & 125.7 \\
\hline & Parameter $c$ & 0.0069 & 0.0090 \\
\hline Null-Accumulation & No. of parameters & 1 & 1 \\
\hline \multirow[t]{3}{*}{$h=c \cdot t$} & Data size & 21 & 21 \\
\hline & $\mathrm{BIC}$ & 138.6 & 159.4 \\
\hline & Parameter $c$ & 0.0001 & 0.0002 \\
\hline Exponential-Constant & No. of parameters & 2 & 2 \\
\hline \multirow[t]{4}{*}{$h=c_{1} \cdot \exp \left(-c_{2} \cdot s\right)$} & Data size & 21 & 21 \\
\hline & $\mathrm{BIC}$ & 79.9 & 93.4 \\
\hline & Parameter $c_{1}$ & $1.710 \mathrm{E}-01$ & $2.483 \mathrm{E}-01$ \\
\hline & Parameter $c_{2}$ & $1.840 \mathrm{E}-01$ & $1.818 \mathrm{E}-01$ \\
\hline Exponential-Accumulation & No. of parameters & 2 & 2 \\
\hline \multirow[t]{4}{*}{$h=c_{1} \cdot \exp \left(-c_{2} \cdot s\right) \cdot t$} & Data size & 21 & 21 \\
\hline & $\mathrm{BIC}$ & 78.1 & 91.5 \\
\hline & Parameter $c_{1}$ & $3.373 \mathrm{E}-02$ & $4.755 \mathrm{E}-02$ \\
\hline & Parameter $c_{2}$ & $2.975 \mathrm{E}-01$ & $2.802 \mathrm{E}-01$ \\
\hline Stepwise-Constant & No. of parameters & 3 & 3 \\
\hline \multirow[t]{5}{*}{$h=c_{1}+c_{2} \cdot f(s, \tau)$} & Data size & 21 & 21 \\
\hline & $\mathrm{BIC}$ & 73.8 & 93.2 \\
\hline & Parameter $c_{1}$ & $6.899 \mathrm{E}-04$ & $8.162 \mathrm{E}-05$ \\
\hline & Parameter $c_{2}$ & $6.771 \mathrm{E}-02$ & 0.0401171 \\
\hline & Parameter $\tau$ & $15.9-17.7$ & $21.3-22.3$ \\
\hline Stepwise-Accumulation & No. of parameters & 3 & 3 \\
\hline \multirow[t]{5}{*}{$h=\left\{c_{1}+c_{2} \cdot f(s, \tau)\right\} \cdot t$} & Data size & 21 & 21 \\
\hline & $\mathrm{BIC}$ & 61.4 & 90.7 \\
\hline & Parameter $c_{1}$ & $1.012 \mathrm{E}-05$ & $1.210 \mathrm{E}-05$ \\
\hline & Parameter $c_{2}$ & $9.046 \mathrm{E}-03$ & $4.245 \mathrm{E}-03$ \\
\hline & Parameter $\tau$ & $15.9-17.7$ & $18.6-21.3$ \\
\hline
\end{tabular}

$h$ hazard or instantaneous mortality rate, $c, c_{1}, c_{2}$ parameters for the effect of salinity, $\tau$ threshold of salinity (determined as a range), $s$ salinity, $f(s, \tau)$ step function ( 1 when $s<\tau$, and 0 when $s \geq \tau)$. The lowest BIC for each temperature is shown in bold numericals 
were either similar (the low temperature) or longer (the high temperature) compared to those for the gradualsalinity-decrease experiment (Fig. 3).

\section{Discussion}

Based on the previous and present experiments in which A. pectinata were exposed to low salinities with no sediment, it is possible to compare hyposaline endurance between juveniles vs. adults, 12 vs. $24{ }^{\circ} \mathrm{C}$, and gradual vs. sharp decreases in salinity, as follows.

Juvenile A. pectinata are likely to be more vulnerable to low salinity than adult A. pectinata. We found that most juvenile $A$. pectinata died within $60 \mathrm{~h}$ at salinities below a threshold existing between 15 and $21 \mathrm{ppt}$ (water temperature 12 and $24^{\circ} \mathrm{C}$; rapid and gradual salinity decrease). On the other hand, Yamamoto and Handa (2011) found that adult $A$. pectinata died at salinities $<15$ ppt but not at salinities $\geq 15$ ppt in an experiment of $96 \mathrm{~h}$ at $28{ }^{\circ} \mathrm{C}$ with a rapid decrease in salinity. That is, juvenile $A$. pectinata died earlier than adult $A$. pectinata at higher salinities. Such a difference between juveniles and adults might have been greater, if juvenile $A$. pectinata had been exposed to low salinities at the high temperature, $28{ }^{\circ} \mathrm{C}$, as with adult $A$. pectinata, because the hyposaline endurance of juvenile A. pectinata is likely to be weakened at higher temperatures (Fig. 3). Such a vulnerability of juvenile bivalves against low salinities was also reported for Perna viridis and Mytella charruana (Yuan et al. 2016).

What is the mechanism explaining the difference in hyposaline endurance between juvenile and adult $A$. pectinata? Bivalves protect themselves against environmental hyposaline water by means of: (1) preventing the hyposaline water from flowing on their soft tissue through valve closure and through ceasing pumping behavior; and/or (2) decreasing the osmotic pressure in their soft tissue cells to the osmotic pressure in the environmental water (Gosling 2003). A. pectinata is reported to adopt the former method at least (Yamamoto and Handa 2011). This method leads to a decreased supply of oxygen to the cells (Yamamoto and Handa 2011). The decreased supply of oxygen is likely to be more stressful for juvenile A. pectinata than for adult $A$. pectinata, since the juveniles die more quickly under hypoxia than the adults (Nagasoe et al. 2017; Nagasoe et al., in preparation). Hypoxia as an outcome of hyposaline water is suggested from the result of the statistical model selection. The selected models in general showed that the hazard (i.e., instantaneous mortality rate) of juvenile A. pectinata soars when salinity decreases below a threshold. This result may mean that the juveniles close their valves and stop water intake in salinities below the threshold, which results in suffering from gradual hypoxia. It is unclear which, juveniles or adults, are more adversely affected when they adopt the second method, namely, regulation of osmotic pressure. This is because there has been no study on osmoregulation for Atrina to our knowledge.

The difference found for LT50 between water temperatures indicates that the hyposaline endurance of juvenile $A$. pectinata with no sediments is weaker at $24{ }^{\circ} \mathrm{C}$ than $12{ }^{\circ} \mathrm{C}$. Such a dependence of hyposaline endurance on water temperature is also reported for Aequipecten opercularis (Gosling 2003), Perna viridis and Mytella charruana (Yuan et al. 2016). A possible explanation for the decreased hyposaline endurance of juvenile A. pectinata at the higher temperature is related with metabolism. A. pectinata would increase their metabolism at the higher temperature, considering that animals (Schmidt-Nielsen 1997), including bivalves (Gosling 2003), increase their metabolism as the ambient temperature increases within a temperature range of their suitable habitat. To address the increased metabolism, A. pectinata would more strongly require oxygen. Such a stronger demand would not be met if $A$. pectinata stop their respiration at low salinities (Yamamoto and Handa 2011), which is likely to be more stressful. An additional, possible explanation for the decreased hyposaline endurance at the higher temperature is related with the van't Hoff's law. According to this law, osmotic pressure increases with temperature, so that the difference in osmotic pressure between the inside and outside of A. pectinata cells should increase, which may be more stressful for A. pectinata.

The LT50 estimated for the rapid-salinity-decrease experiment were either similar (the low temperature) or longer (the high temperature) compared to those for the gradual-salinity-decrease experiment. This is an unexpected result, considering that a more rapid decrease in salinity is likely to lead to a more acute effect of osmotic pressure on cells (Shumway et al. 1977) and to be more stressful. The result is unlikely due to the artifact that experimental period was longer for the rapid-salinity-decrease experiment $(140 \mathrm{~h})$ than the gradual-salinity-decrease experiment $(120 \mathrm{~h})$. This is because no specimen died between 120 and $140 \mathrm{~h}$ in the 
rapid-salinity-decrease experiment (Fig. 4), and thus the estimates of LT50 for this experiment would not change much even if the experimental period was reduced from 140 to $120 \mathrm{~h}$. In the gradual-salinity-decrease experiment, perhaps, water in rearing cups was frequently agitated owing to the little-by-little dilution of salinity, which might have been stressful for juvenile A. pectinata.

Our data give suggestions for the stock enhancement of A. pectinata in the Ariake Sea. It should take into account that juvenile $A$. pectinata are vulnerable to low salinities $<21$ ppt especially for $24{ }^{\circ} \mathrm{C}$, at least when the specimens are not embedded in sediment. Therefore, juvenile A. pectinata should not be transplanted onto the tidal flat of the Ariake Sea in the rainy season and neighborhood of rivers leading to salinities $<21 \mathrm{ppt}$ (Fisheries Research Agency and Saga University 2012). In addition, juvenile A. pectinata should not be kept in rearing systems where incidental intake of hyposaline water may occur. Some rearing systems near the Ariake Sea use underground seawater, which occasionally has salinity $<20$ ppt (Kurihara, personal data). The abovementioned transplantation and rearing should be avoided especially for seasons with the water temperature $\approx 24{ }^{\circ} \mathrm{C}$. In the present study, juvenile A. pectinata were not embedded in sediments. Future study should examine the possibility that juvenile $A$. pectinata surrounded by sediments are affected by the salinities of not only water column but also the interstice water in sediments.

Acknowledgements We thank Dr. Junya Hiroi and Dr. Masahiko Matsuda for their information on hyposaline endurance of aquatic organisms. We thank Dr. Sou Nagasoe for his information on tolerance to starvation and hypoxia in A. pectinata. We thank Fukuoka Fisheries and Marine Technology Research Center and Saga Prefectural Ariake Fisheries Research and Development Center for providing adult Atrina spp. for the artificial hatchery. This study was funded by the "Nimaigai Kinkyu Zoshoku Taisaku Jigyo" from Japan Fisheries Agency.

Open Access This article is distributed under the terms of the Creative Commons Attribution 4.0 International License (http:// creativecommons.org/licenses/by/4.0/), which permits unrestricted use, distribution, and reproduction in any medium, provided you give appropriate credit to the original author(s) and the source, provide a link to the Creative Commons license, and indicate if changes were made.

\section{References}

Aramaki H (2013) The relationship between an effect of DNA analysis and proportion of pen-shells, Atrina spp. in the innermost area of Ariake Bay. Ariake Fish Promot Center Res Rep 26:89-91 (in Japanese)

Aramaki H, Tsukuda M (2014) The transplantation of pen-shells, Atrina spp. to tidal flats of the inner part of Ariake Bay in Saga Prefecture. Ariake Fish Promot Center Res Rep 27:1-8 (in Japanese)

Dobson AJ, Barnett A (2008) An introduction to generalized linear models, 3rd edn. Chapman \& Hall, Florida

Fisheries Research Agency, Saga University (2012) Investigation for a plan to restore the ecosystem of Ariake Bay (evaluation of ecological functions of bivalves). In: Report of the results for contract research of Ministry of the Environment

Fisheries Research Agency, Seikai National Fisheries Research Institute, National Research Institute of Fisheries and Environment of Inland Sea, Fukuoka Fisheries and Marine Technology Research Center, Saga Ariake Fisheries Promotion Center, Nagasaki Prefectural Institute of Fisheries, Kumamoto Fisheries Research Center (2017) Nimaigai Shigen Kinkyu Zosyoku Taisaku Itaku Jigyo Hokokusyo. Fisheries Agency

Funakoshi S, Suzuki T, Wada K (1985) Salinity tolerances of marine bivalves. In: Sindermann CJ (ed) Environmental quality and aquaculture systems. Proceedings of the 13th US-Japan meeting aquaculture, Mie, 24-25 October 1984. NOAA technical report NMFS 69. US Department of Commerce, NOAA, National Marine Fisheries Service, Springfield, pp 15-18

Gillanders BM, Kingsford MJ (2002) Impact of changes in flow of freshwater on estuarine and open coastal habitats and the associated organisms. Oceanogr Mar Biol 40:233-309

Gosling E (2003) Bivalve molluscs (biology, ecology and culture). Fishing News Books, a division of Blackwell Publishing, Oxford. http://malacolog.com/files/Gosling_2004.pdf. Accessed 22 Jun 2017

Holmes SP, Miller N (2006) Aspects of the ecology and population genetics of the bivalve Corbula gibba. Mar Ecol Prog Ser 315:129-140

Jansen JM, Koutstaal A, Bonga SW, Hummel H (2009) Salinity-related growth rates in populations of the European clam Macoma balthica and in field transplant experiments along the Baltic Sea salinity gradient. Mar Freshw Behav Physiol 42:157-166

Yamamoto K, Handa T (2011) Effect of low salinity in ambient water on ventilation in the pen-shell Atrina (Servatrina) lischkeana. Suisan Zosyoku (Aquacult Sci) 59:535-540 (in Japanese with English abstract)

Kinne O (1966) Physiological aspects of animal life in estuaries with special reference to salinity. Neth J Sea Res 3:222-244

Kleinbaum DG, Klein M (2012) Survival analysis: a self-learning text. Springer, New York

Koga H, Aramaki H (2013) History of the pen shell, Atrina spp. fishery and the factors relevant to the fishing ground formation in Saga Ariake Bay-especially, some considerations about the factors of big catch in 2009 fiscal fishing period. Ariake Fish Promot Center Res Rep 26:13-24 (in Japanese with English abstract)

Kurihara T (2017) Tolerance of the bivalve Trapezium liratum (Reeve, 1843) to decrease in salinity. Plankton Benthos Res 12:44-52 
Lemer S, Buge B, Bemis A, Giribet G (2014) First molecular phylogeny of the circumtropical bivalve family Pinnidae (mollusca, bivalvia): evidence for high levels of cryptic species diversity. Mol Phylogen Evol 75:11-23

Leyva-Valencia I, Maeda-Martinez AN, Sicard MT, Roldan L, Robles-Mungaray M (2001) Halotolerance, upper thermotolerance, and optimum temperature for growth of the penshell Atrina maura (Sowerby, 1835) (Bivalvia: Pinnidae). J Shellfish Res 20:49-54

Liu J, Li Q, Kong LF, Zheng XD (2011) Cryptic diversity in the pen shell Atrina pectinata (Bivalvia: Pinnidae): high divergence and hybridization revealed by molecular and morphological data. Mol Ecol 20:4332-4345

Marsden ID (2004) Effects of reduced salinity and seston availability on growth of the New Zealand little-neck clam Austrovenus stutchburyi. Mar Ecol Prog Ser 266:157-171

Matsuda M, Shinagawa A, Higano J, Fujii A, Hirano K, Ishimatsu A (2008) Effects of low salinity on survival, hemolymph osmolality and tissue water content of the manila clam Ruditapes philippinarum. Suisan Zosyoku (Aquacult Sci) 56:127-136 (in Japanese with English abstract)

McLeod RJ, Wing TR (2008) Influence of an altered salinity regime on the population structure of two infaunal bivalve species. Estur Coast Shelf S 78:529-540

Nagasoe S, Tokunaga T, Matsuyama Y (2017) Effect of hypoxic conditions on the survival of juvenile pen shell Atrina cf. japonica (an East Asian species). Suisan Zosyoku (Aquacult Sci) 65 (in press)

Newell RC (1976) Adaptation to environment: essays on the physiology of marine animals. Butter Worths, London

Paul JD (1980) Salinity-temperature relationships in the queen scallop Chlamys opercularis. Mar Biol 56:295-300

R Core Team (2015) R: a language and environment for statistical computing. R Foundation for Statistical Computing, Vienna. http://www.R-project.org/. Accessed 22 Jun 2017

Rupp GS, Parsons GJ (2004) Effects of salinity and temperature on the survival and byssal attachment of the lion's paw scallop Nodipecten nodosus at its southern distribution limit. J Exp Mar Biol Ecol 309:173-198

Schmidt-Nielsen K (1997) Animal physiology: adaptation and environment, 5th edn. Cambridge University Press, Cambridge

Shumway SE, Gabbott PA, Youngson A (1977) Effect of fluctuating salinity on concentrations of free amino-acids and ninhydrinpositive substances in adductor muscles of 8 species of bivalve mollusks. J Exp Mar Biol Ecol 29:131-150

Upton G, Cook I (2005) Dictionary of statistics, 2nd edn. Oxford University Press, Oxford

Yoshida M, Ito T, Chikushi Y (2007) The study of transplantation of the pen-shell (Atrina pectinata japonica). Bull Fukuoka Fish Mar Tech Res Center 17:1-5 (in Japanese)

Yuan W, Walters LJ, Schneider KR, Hoffman EA (2010) Exploring the survival threshold: a study of salinity tolerance of the nonnative mussel Mytella charruana. J Shellfish Res 29:415-422

Yuan WS, Walters LJ, Brodsky SA, Schneider KR, Hoffman EA (2016) Synergistic effects of salinity and temperature on the survival of two nonnative bivalve molluscs, Perna viridis (Linnaeus 1758) and Mytella charruana (d'Orbigny, 1846). J Mar Biol. https://doi.org/10.1155/2016/9261309 (Article ID 9261309. Accessed 22 June 2017)

\section{Publisher's Note}

Springer Nature remains neutral with regard to jurisdictional claims in published maps and institutional affiliations. 